\title{
A EDUCAÇÃO SEXUAL E A PROTEÇÃO CONTRA 0 ABUSO
}

\author{
Verônica Lúcia D. Ribeiro de Gusmão' \\ Marcio Ruiz Schiavo ${ }^{2}$ \\ Pedro Jurberg ${ }^{3}$
}

\section{Resumo}

As manifestações da sexualidade, pelas crianças ("jogos sexuais infantis"), parece ser inata, já que se fazem presentes em todas as culturas. Quando a criança considera que a sexualidade é algo reprimido pelos adultos, passa a protegê-la destes, através da clandestinidade. 0 trabalho de orientação sexual contribui para a prevenção de problemas graves, como o abuso sexual. Cientistas reconhecidos, embora citados fora de contexto, passaram a ser usados por grupos defensores da pedofilia, como se estivessem apoiando a idéia de que as relações sexuais entre adultos e crianças nem sempre são prejudiciais a estas, podendo, mesmo, ser benéficas para a formação de sua sexualidade. É necessário que a criança diga sim às brincadeiras sexuais infantis; a fim de que, saciada em suas buscas de conhecimento, descobertas e curiosidades, possa dizer não ao abusador adulto.

\section{A "inocência" das crianças e o abuso sexual}

A respeito das manifestações da sexualidade, pelas crianças ( "jogos sexuais infantis"), cumpre esclarecer que a tentativa da prática destas

\footnotetext{
' Especialista em Sexualidade Humana e Mestre em Sexologia (UGF) 
atividades parece ser inata, já que em todas as culturas se fazem presentes, caso não sejam sumariamente proibidas.

“A proibição das brincadeiras sexuais não evita que elas ocorram, mas as torna clandestinas, levando as crianças a se apalparem no escuro, com sentimento de culpa" (Money \& Tucker, 1981, p. 121).

Quando a criança considera que a sexualidade é algo reprimido pelos adultos, passa a protegê-la destes através da clandestinidade, e esta clandestinidade e desconfiança mútuas são muito perigosas, no que se refere à exposição da criança aos adultos mal intencionados.

"As experiências sexuais de crianças com outras da mesma idade pode ser um fator de segurança. Se o seu filho possui amiguinhos bem ajustados de sua própria idade, você poderá estar certa que as brincadeiras sexuais ocasionais serão balanceadas por todo tipo de outras brincadeiras ... (Calderone, \&t Ramey, 1986, p. 58 ).

Os próprios Parâmetros Curriculares Nacionais, inclusive, em seu capitulo sobre Orientação Sexual - Justificativa, assinalam que : “ 0 trabalho de orientação sexual também contribui para a prevenção de problemas graves como o abuso sexual ..." (Secretaria de Educação Fundamental, MEC, 1998).

0 adulto sociopata e molestador necessita da criança assexuada e "inocente".

"A ignorância sexual, o desconhecimento da existência, significado, possibilidades e variações da cópula e ademais de todo tipo de interação sexual é o que se chama de inocência. 0 elogio da inocência é, pois, o elogio da ignorância, e parece fundamental compatibilizar essa tradição social com a necessidade de aprendizagem, para entender 
como as disfunções sexuais não têm taxas assustadoramente maiores. Essa compatibilização se evidencia nos dados de Kinsey e colaboradores (1948), que em principio ratificam as visões de Ford e Beach (1951), indicando que a aprendizagem é realmente fundamental e que ela efetivamente ocorre, em que pese todo tipo de cuidado e restrição social. A curiosidade e a capacidade de transgredir cumprem seu papel." (Silva, 1980, p. 30).

As crianças devem, desde cedo, conhecer seus próprios corpos e aprender a dizer não a adultos, para se protegerem de abuso sexual. Concordamos que uma “ orientação sexual " mal dirigida, voltada apenas para ressaltar o prazer ligado à sexualidade, pode deixar a criança ainda mais suscetível ao abuso sexual; por outro lado, a política de terror contra qualquer demonstração de ternura, ou toque carinhoso, vindo de um adulto ou adolescente, estranho ou não, poderá marcar e deformar a estrutura da sexualidade da criança.

Os lares, porém, nem sempre cumprem seu papel na educação sexual das crianças, conforme evidencia uma pesquisa do Instituto DataFolha, realizada em dez capitais brasileiras e divulgada em 27 / 06 /93, a qual ..."constatou que $86 \%$ das 5076 pessoas ouvidas são favoráveis à inclusão de orientação sexual nos currículos escolares. Apesar de favoráveis, ou por causa disso mesmo, somente $32 \%$ dos pais conversam sobre sexo com seus filhos; 50 $\%$ nunca chegaram a ter esta conversa." (Fórum Nacional de Educação e Sexualidade, 1994, p.1)

Os casos relatados de molestamento sexual de crianças são apenas a fração visivel de um problema muito maior. Note-se esta advertência: "Num estudo retrospectivo de 1200 mulheres (que )... referiram uma experiência sexual com um adulto, antes da idade de treze anos, ... apenas $6 \%$ destes incidentes foram comunicados às autoridades" ( Gagnon, 1965, p. 176). 
A American Humane Association estimou em 200000 a 300 000, por ano, os casos de molestamento de crianças do sexo feminino nos Estados Unidos. 0 abuso sexual é a forma mais oculta, mais angustiante e mais controversa do abuso de crianças. Nós acreditamos que toda pesquisa que tenha, por objetivo mesmo indireto, aumentar a possibilidade da criança resistir a tal situação, terá sua parcela de relevância.

Na nossa pesquisa bibliográfica, encontramos um grande número de trabalhos cientificos recentes: (Nemerofsky, Carran e Rosenberg, 1994; Gibson \& Bogat, 1994 ; Grober \& Bogat, 1994 ; Boat \& Everson, 1994; Oates et al., 1995; Fitzpatrick, Deehan e Jenkings, 1995; Gagnon, 1995; Collins, 1996; Olafsdottir, 1996 ) que advertem, inclusive, que a educação precoce das crianças nos aspectos da sexualidade, ao alcance de seu entendimento, é importante para protegê-las contra os abusos sexuais e, também, para torná-las aptas em descrever, com assertividade, os atos relacionados ou não com abuso, a que forem submetidas.

Cabem, aqui, algumas considerações sobre o abuso sexual da criança, já que, conforme já assinalamos, a satisfação da curiosidade das crianças acerca dos fatos de natureza sexual, bem como a permissão e a aceitação de que conheçam a anatomia e explorem as sensações do próprio corpo e de seus colegas de idade aproximada, são requerimentos indispensáveis para protegê-la do adulto ou do adolescente molestadores.

“0 abuso sexual é uma situação em que uma criança ou adolescente é usado para gratificação sexual de um adulto ou mesmo de um adolescente mais velho, baseado em uma relação de poder que pode incluir desde caricias, manipulação da genitália, mama ou ânus, exploração sexual, "voyeurismo", pornografia e exibicionismo, até o ato sexual com ou sem penetração, com ou sem violência. A etiologia e os fatores determinantes do abuso sexual contra a criança e o adolescente tem implicações diversas. 
Envolvem questões culturais (como é o caso do incesto) e de relacionamento (dependência social e afetiva entre os membros da família), o que dificulta a notificação e perpetua o "muro do silêncio". Envolvem questões de sexualidade, seja da criança, do adolescente ou dos pais, e da complexa dinâmica familiar". (ABRAPIA, 1997. p. 7).

A literatura médico - científica sobre abuso sexual, assim como estatísticas e pesquisas a respeito, são reduzidas, no Brasil; a incidência real das vitimas é quase desconhecida, no nosso meio. Alguns números, porém, apresentados em estudos, indicam que sua ocorrência é algo que não pode mais ser ignorado.

O CRAMI - Centro Regional de Atenção aos Maus Tratos na Infância de Campinas, S.P. - estima que, entre 1.251 crianças atendidas no Instituto Médico Legal de Campinas, vitimas de abuso sexual, $31.7 \%$ tinham entre 2 e 7 anos de idade (ABRAPIA, 1997, p. 6).

\section{A pedofilia e sua discussão}

0 abuso sexual de crianças abarca séculos e continentes. 0 fato novo foi que, na década de 60 , este fenômeno foi formalmente identificado e que suas várias formas de expressão começaram a ser objeto de estudo.

Nos Estados Unidos, na década de 70, aumentou a discussão acerca da pornografia infantil, em função de um número crescente de pedófilos (pessoas que apresentam o tipo de anomalia sexual onde o objeto preferido é a criança) que decidiram ver aceitas socialmente e legalizadas as suas práticas. Calcados na afirmação de que suas atividades embasavam-se em sentimentos naturais e inofensivos, este grupo de pessoas organizou-se e produziu amplo material informativo, com o objetivo de alterar a legislação vigente no país. ( ABRAPIA, 1997).

Cientistas reconhecidos, como John Money, (da The Johns Hopkins University), Larry Constantine, (da Tufts University), Wardell Pomeroy, 
(co-autor do Relatório Kinsey) e Yehudi Cohen, (antropólogo da Rutgers University), passaram a ser citados como defensores da idéia de que as relações sexuais entre adultos e crianças nem sempre são prejudiciais a estas, podendo, mesmo, ser benéficas para a formação de sua sexualidade (Bass e Thorton, 1985 ).

0 ponto que não era abordado, no qual ficava a meia verdade, utilizada para distorcer as palavras dos cientistas e colocá-las fora de contexto, é que nenhuma relação entre adultos e crianças, ou entre crianças e adolescentes bem mais velhos, permite uma igualdade de poder. $\mathrm{E}$ onde não há igualdade de poder, há coerção.

A relação, seja sexual ou não, que pressupõe coerção, vai atender às necessidades do que coage, nunca do coagido. Dificilmente deixará de ser traumática e prejudicial ao mais fraco. A expressão sexual da criança, até por razões biológicas e anatômicas, não prevê a relação sexual, conforme a deseja o adulto. A criança ainda não possui o substrato de imaginação, memórias e desejos necessários para se sentir excitada sexualmente, e o prazer, que porventura venha a sentir com as carícias do adulto, normalmente será mais fugaz do que aquele de que precisaria, para acompanhar o seu parceiro.

A partir de certo momento, ou desde o início do episódio de abuso, a submissão da criança dever-se-á à força física superior do outro, seu medo de desagradar ao adulto, seu temor das conseqüências de sua resistência, sua vergonha pelo que estará acontecendo, sua tendência natural para obedecer, seu conflito, confusão, insegurança e angústia. Por razões óbvias, receberá recomendações e ameaças, para não comentar com ninguém o acontecido e perceberá que fora cúmplice de um ato inaceitável pela sociedade, passando a associar as expressões da sexualidade com os sentimentos de vergonha, angústia, medo e, até, nojo, dor e desprazer. 
Deixando de confiar nos adultos que respeita e conhece, deixará de confiar no mundo. Cabe aqui uma importante advertência. Os sentimentos negativos, relacionados com a sexualidade, que foram citados acima (vergonha, medo, angústia, nojo, dor, desprazer) bem como a perda da confiança e da segurança naturais da criança, poderão e serão produzidos, com a mesma eficácia, por "programas para ensinar às crianças a refutar um ataque sexual", treinamentos exagerados e mal conduzidos, implementados por genitores aterrorizados e motivados por publicações e associações extremistas, na defesa da "inocência", da "pureza e da "autenticidade" das crianças.

Em livros e revistas publicados, muitas vezes, por organizações orientadas por defensores de outras idéias (como o feminismo ou a defesa da ecologia), mensagens assustadoras são divulgadas, em termos eivados de alarmismo e de preconceitos, dando origem a terrores que acabam sendo repassados às crianças.

Observemos os textos seguintes, que são exemplos do que acabamos de citar:

"Estamos em perigo. Neste livro, dizemos não à profanação. ... Não viramos o rosto para evitar a dor. As estatísticas, por todos os horrores que implicam, podem ser tão vastas que nos protegem das vidas individuais que os números representam. Queriamos que as estatisticas se tornassem mais reais, desejávamos mostrar a dor dos indivíduos. Em certos momentos, a enormidade da tarefa esmagou-nos. Não é fácil se abrir para o conhecimento de que milhões de crianças são violentadas. ... Estamos em perigo. Nossas filhas correm perigo. Até nossos filhos estão ameaçados. Atrás de cada estatística existe uma criança. Ela pode ser você, sua filha, sua irmã, ou uma amiga sua. Você não poderá protegê-la até podermos proteger todas as crianças “. (Bass e Thorton, 1985, p. $27-28$ ). 
As mensagens assustadoras, às vezes, vêm mescladas pelo terrorismo ecológico, pelo antagonismo aos homens ou pela ameaça de catástrofe nuclear :

"Em um mundo poluído, provavelmente de forma irrecuperável, e no qual a saúde das próximas gerações está hipotecada para termos carros e aparelhos elétricos, é perfeitamente coerente que muitos homens façam coisas degradantes com crianças. ... 0 abuso sexual de crianças é parte de uma cultura na qual se tolera a violência contra a vida. Nossas florestas, rios, oceanos, ar e terras, toda a biosfera está sendo invadida por venenos - violentada, como nossas filhas estão sendo estupradas. É bem provável que dentro de cinqüenta anos ou menos, não exista mais vida, pelo menos como a conhecemos, na Terra. Uma guerra nuclear pode matar a todos nós. Mesmo sem a explosão de uma bomba, a radiação emitida nas várias fases da extração de minérios radioativos, fresagem e construção de usinas nucleares e armamentos já é tão abundante que a continuação da espécie corre um grave perigo. Não há o que estranhar em homens, cujo desejo de lucro substituiu seu instinto de sobrevivência, que se aproveitem sexualmente dos jovens." (Ibidem, p. 32 - 33 ).

Vemos, pois, como é delicado e difícil o equilibrio entre a atitude de aceitação das manifestações da sexualidade, nas crianças, e uma facilitação para que adultos mal intencionados tentem aproveitar-se delas, para atender às suas necessidades de sexo associado à dominação e à violência.

\section{O conhecimento do corpo como defesa contra o abuso}

A omissão da família e da escola produz a ignorância, que é confundida pela sociedade adulta como inocência. Considerando a quantidade de informações que bombardeiam os individuos, em nossos dias, 
(provenientes, principalmente, da televisão), é curioso que alguns pais ainda mantenham a ilusão da possibilidade da "inocência" e ainda valorizem esta forma de ignorância, nas mulheres e nas crianças. 0 que vemos, na prática, é que, em nenhum momento, a educação infantil se orienta para o conhecimento, pela criança, do seu próprio corpo e muito menos se aceitam as brincadeiras sexuais infantis com outra criança, na mesma fase de desenvolvimento, como necessárias para o desenvolvimento psico-sexual (Gusmão, 2000).

A família, a televisão e a escola - responsáveis pela educação infantil não esclarecem sobre o abuso e muito menos falam sobre as formas de evitá-lo (Schiavo,1997). É necessário que o adulto perceba que uma das formas da criança se fortalecer, diante do abusador, é através do conhecimento: o conhecimento que, entre os dois e os seis anos de idade, se constrói através da relação concreta com seu próprio corpo e da descoberta do corpo de outra criança.

Compreender e aceitar os jogos sexuais infantis é permitir que a sua sexualidade saia da clandestinidade, que a criança descubra, sem culpa, as áreas prazerosas do seu corpo. É necessário que a criança se sinta "autorizada", que seja "orientada", para que tome posse do seu corpo, para que diga sim aos seus próprios "toques", diga sim às brincadeiras sexuais infantis; a fim de que, saciada em suas buscas de conhecimento, descobertas e curiosidades, possa dizer não ao abusador que, geralmente, está dentro de casa, na figura do pai, da mãe, do tio, do irmão ou de algum adolescente ou adulto próximos. Educar e orientar para a sexualidade infantil é falar sobre a realidade e permitir que as sensações ligadas à sexualidade sejam reais e conhecidas, para a criança. Porque é por ai que entra o abusador, pois pode aproveitar-se da ignorância da criança e das novas sensações de prazer que lhe pode proporcionar.

É necessário diferenciarmos prazer corporal de apetite sexual. 0 apetite sexual está relacionado a ações hormonais e psíquicas, que ainda não 
fazem parte deste momento da criança. 0 apetite sexual está ligado ao desejo (imaginação, simbolização), que são inacessiveis à criança até por volta dos seis anos, enquanto que o prazer corporal é físico e psíquico, acessivel à criança. Marilena Chaui (1984), discorrendo sobre repressão da sexualidade, serve de apoio para esta nossa afirmação :

“As práticas sociais de controle, proibição e permissão do sexo, são antiqüíssimas, porém, o estudo de seu espirito, de suas causas, de suas variações no tempo e no espaço é recente, não sendo casual que os dicionários registrem como tardio o surgimento da palavra sexualidade, momento em que o termo sexo passa a ter um sentido muito alargado, especialmente quando os estudiosos passaram a distinguir e diferenciar entre necessidade (fisica, biológica), prazer (fisico, psiquico ) e desejo (imaginação, simbolização)". (op.cit: 11).

É preciso entender que a curiosidade da criança e o seu interesse em saber sobre as coisas da sexualidade, são coisas também diferentes de apetite sexual. Não possuir as informações corretas, não obter respostas, ser reprimida na curiosidade infantil, manter idéias erradas em relação ao corpo, reforça a ignorância e a desprotege para a vida, em nome do mito da inocência.

Os abusos, na maioria das vezes, são efetivados sem violência física e realizados por pessoas que identificam, na criança, um alvo frágil que permite cumplicidade. A criança é, assim, desprotegida, pela ausência de esclarecimento das formas de dizer não e de não ter podido exercer o reconhecimento do seu próprio corpo.

Sara Paim (1999) distingue corpo de organismo, e diz que um organismo é comparável a um aparelho de recepção programada, que possui transmissores (células nervosas) capazes de registrar certos tipos de informações e reproduzi-las, quando necessário. Já o corpo não se reduz a este aparato somático; é o organismo que, quando atravessado 
pelo desejo e pela inteligência, compõe uma corporeidade, um corpo que aprende, que pensa, que atua.

0 funcionamento do corpo é aprendido. 0 organismo necessita do corpo, como um instrumento musical necessita de um músico, que lhe permita emitir o som para o qual foi construido. Pelo corpo, nos apropriamos do organismo. É isto que a criança deve aprender a fazer: dominar seu corpo pela consciência do poder que adquire sobre ele.

A aprendizagem inclui sempre o corpo, porque inclui o prazer e este está no corpo. Não há aprendizagem que não esteja registrada no corpo. A participação do corpo no processo de aprendizagem se dá pela ação (principalmente nos primeiros anos do desenvolvimento infantil) e pela representação. Todo conhecimento tem um nivel de ação (fazer os movimentos) e um nível figurativo (dado pela imagem, pela configuração) que se inscreve no corpo.

As informações e ensinamentos que são "descorporizados" tiram todo interesse do que é transmitido e rapidamente são esquecidos. Luiz 0. Pérez Flores afirma, ao discutir sobre abuso sexual infantil na conferência: Um Nuevo Programa de Prevencion Del Abuso Sexual para Latinoamérica, no VII Congresso Brasileiro de Sexualidade Humana, 1999 :"- A criança abusada busca, muitas vezes, ser abusada novamente".

Em certo sentido, a criança abusada legitima o adulto abusador na realização da produção do prazer, quando se sente dominada, não pela força física do abusador, mas pela força do prazer desconhecido que aquele toque gera no seu corpo. Impotente diante da força daquele toque "mágico", proibido de ela mesma realizar, sente-se dividida, angustiada, ante o medo de denunciar o ato e a culpa de ter obtido o prazer da sensação. 0 efeito traumático do abuso é gerado, também, pela relação que a criança estabelece entre o medo de ser descoberta e, mais tarde, o sentimento de quebra de normas morais e sociais. 
Se a criança percebe que os adultos mentem sobre os assuntos ligados à sexualidade ( e como percebe !), deduz que ela também pode e deve fazê-lo. Começam, então, as práticas sexuais secretas, os hábitos da mentira e da dissimulação, assim como o medo e a angústia causados pelo sentimento de culpa. A confiança, tão importante para que o jovem procure o conselho dos pais, quando em dificuldades, começa a deteriorar-se, junto com a amizade e a intimidade que seriam desejáveis para uma mútua compreensão (Atucha e Schiavo, 1994).

Quando aparecem as mudanças corporais da puberdade, a primeira menstruação, a masturbação saudável e natural, o jovem é conduzido para uma situação de isolamento, ignorância, culpa e perda de auto-estima, que seriam perfeitamente evitadas com um posicionamento mais apropriado, dos adultos, ante as manifestações iniciais da sexualidade.

A repressão gera, na criança, o sentimento de que o sexo é algo a ser evitado, transformado em clandestino, até mesmo quando apenas falado. A curiosidade da criança é inocente e legitima. Os pais, a sociedade e a escola devem respeitar esta curiosidade.

\section{Referências Bibliográficas}

ABRAPIA (ASSOCIAÇÃO BRASILEIRA MULTIPROFISSIONAL DE PROTEÇÃO À INFÂNCIA E ADOLESCÊNCIA. Abuso Sexual Contra Crianças e Adolescentes. IN L. Monteiro Filho e V. Abreu (Coords.). Petrópolis : Autores e Agentes e Associados, 1997.

ATUCHA, L., SCHIAVO, M. Sexualmente Irreverentes. Rio de Janeiro: Comunicarte, 1994.

BASS, E. e THORNTON, L. Nunca Contei a Ninguém. São Paulo: Harper e Row do Brasil, 1985.

BOAT, B., EVERSON, M. Exploration of Anatomical Dolls by Nonreferred Preschool - Aged Children: Comparisons by Age, Gender, Race, and 
Socioeconomic Status Child. Abuse and Neglect. 18 (2): 139-153, 1994. CALDERONE, M., RAMEY, J. Falando com seu filho sobre Sexo: Perguntas e Respostas para crianças, do nascimento até a puberdade. São Paulo: Summus, 1986.

CHAUI,M. Repressão Sexual, essa nossa (des)conhecida. São Paulo: Brasiliense, 1984.

COLLINS, M. Parent's Perceptions of the Risk of Child Sexual Abuse and Their Protective Behaviors: Findings from a Qualitative Stud., Child Maltreatment. 1 (1): 53-64,1996.

FITZPATRICK, C., DEEHAN, A., JENKINGS, S. Children's Sexual Behaviour and Knowledge: A Community Study. Irish Journal of Psychological Medicine. 87-91, 1997.

FORD, C., BEACH, F. Patterns of sexual behavior. New York: Harper \& Row, 1951.

FÓRUM NACIONAL DE EDUCAÇÃO E SEXUALIDADE Guia de Orientação Sexual. Diretrizes e Metodologia da Pré-Escola ao $2^{\circ}$ Grau. São Paulo: GTPOS, ABIA e ECOS, 1994.

GAGNON, J. Female Child Victims of Sex Offenses. Social Problems. 13: 176-192, 1965

GIBSON, G., BOGAT, A. Pretesting Effects in the Evaluation of a Sexual Abuse Education Program for Preschool Children, Journal of Child Sexual Abuse. 2 (3): 15-31,1993.

GROBER, J., BOGAT, A. Social Problem Solving in Unsafe Situations: Implications for Sexual Abuse Education Programs. American Journal of Community Psychology. 22(3): 399-414, 1994.

GUSMÃO, V. A atitude dos adultos ante as manifestações da sexualidade infantil, na área urbana do Rio de Janeiro. Rio de Janeiro: Mestrado em Sexologia da Universidade Gama Filho, 2000. Dissertação de Mestrado. KINSEY, A., POMEROY, C., MARTIN, C. Conduta Sexual da Mulher. Rio de Janeiro: Atheneu, 1954.

MONEY, J., TUCKER, P. Os Papéis Sexuais. São Paulo: Brasiliense, 1981. NEMEROFSKY, A., CARRAN, D., ROSENBERG, L. Age Variation in Performance Among Preschool Children in a Sexual Abuse Prevention Program. Journal of Child Sexual Abuse. 3(1): 85-102, 1994. 
OATES, R., GRAY, J., SCHWEITZER, L. A Therapeutic Preschool for Abused Children: The Keepsafe Project. Child Abuse and Neglect. 19, (11): 1379-1386, 1995.

OLAFSDOTTIR, M. Kids Are Both Girls and Boys. Iceland Women's Studies International Forum 19 (4): 357-369, 1996.

PAÍM, S. A Função da Ignorância. Porto Alegre: Artes Médicas Sul, 1999. SCHIAVO, M. Pesquisa Sobre Erotismo, Sexualidade \&t Relações de Gênero na Programação Infantil das Emissoras de TV (Relatório Quantitativo e Qualitativo). Rio de Janeiro: Comunicarte, 1997.

SECRETARIA DE EDUCAÇÃO FUNDAMENTAL. (Brasil). Parâmetros Curriculares Nacionais: Orientação Sexual. Brasilia: MEC/SEF, 1997 SILVA, A. Sexualidade Humana Comparada: Fundamentos Bioantropológicos da Terapia Sexual. Rio de Janeiro: Achiamé, 1980. 